\title{
METODOLOGIAS ALTERNATIVAS PARA O ENSINO DE GENÉTICA EM UM CURSO DE LICENCIATURA: um estudo em uma universidade pública de Minas Gerais
}

\author{
Handilany T. de Araújo Souza de OLIVEIRA ${ }^{1}$ \\ Keli Eloide FERREIRA ${ }^{2}$ \\ Paloma Aparecida de Castro RIBEIRO ${ }^{3}$ \\ Marina Lorentz ROCHA ${ }^{4}$ \\ Fernanda de Jesus COSTA ${ }^{5}$ \\ Érica Molfetti MARTINS ${ }^{6}$
}

${ }^{1}$ Estudante de Ciencias Biológicas, handilany@ gmail.com
${ }_{2}$ Estudante de Ciências Biológicas, kelipiu@ hotmail.com
${ }^{3}$ Estudante de Ciências Biológicas, palomaribeiro-@ @otmail.com
${ }^{4}$ Estudante de Ciências Biológicas, marina_lorentz@ @otmail.com
${ }^{5}$ Professora da Universidade do Estado de Minas Gerais, fernanda.costa@ @emg.br
${ }^{6}$ Professora da Universidade do Estado de Minas Gerais, erica.molfetti@yahoo.com.br

Recebido em: 23/02/2016 - Aprovado em: 22/03/2017 - Disponibilizado em: 01/07/2017

\begin{abstract}
RESUMO
A genética é uma disciplina que atrai alunos de diversos níveis, devido aos conhecimentos que ela proporciona. Apesar disto, os processos de ensino e aprendizagem desta disciplina não vêm sendo realizados de forma satisfatória no ensino básico e nem mesmo na graduação, em ambos níveis, muitas vezes os alunos não são capazes de aplicar os conhecimentos obtidos. Acreditamos que esta dificuldade esteja relacionada com a não utilização de metodologias diferenciadas, os professores tendem a utilizar apenas a aula expositiva. Assim, buscamos realizar uma oficina com estudantes de licenciatura com o objetivo de verificar a eficácia de novas metodologias no ensino de genética. Foi possível perceber que metodologias alternativas favorecem os processos de ensino e aprendizagem de genética. Acreditamos que os professores dos cursos de licenciatura devem utilizar estas possibilidades em suas práticas docentes com o objetivo de demonstrar para seus alunos, futuros professores, novas opções para os processos de ensino.
\end{abstract}

Palavras-Chave: Formação de professores, ensino de genética, metodologias alternativas

\begin{abstract}
:
Genetics is a discipline that attracts students of different levels, due to the knowledge that it provides. Nevertheless, teaching processes and learning of this discipline are not being satisfactorily achieved in basic education and even graduation, on both levels, students often are not able to apply the knowledge obtained. We believe that this difficulty is related to the non-use of different methodologies, teachers tend to use only the lecture. So we made a workshop with undergraduate students in order to verify the effectiveness of new methods in genetics education. It was revealed that alternative methodologies favoring the processes of teaching and learning genetics. We believe that teachers' degree courses should use these possibilities in their teaching practices in order to demonstrate to their students, future teachers, new options for teaching processes.
\end{abstract}

Keywords: Teacher training, genetics education, alternative methodologies 


\section{Introdução}

A sociedade na qual estamos inseridos vem passando por mudanças ambientais, científicas, tecnológicas e sociais, assim, é preciso que o ensino de Ciências apresente importância fundamental (VIVEIRO, CAMPOS, 2014), pois é através dele que o indivíduo adquire conhecimentos científicos e torna-se capaz de viver com qualidade na sociedade. Considerando esta importância e necessidade, o ensino de genética ganha destaque e precisa ser repensado nas escolas básicas e também em cursos de formação de professores.

A genética é uma disciplina que atrai diferentes públicos, desde alunos do ensino fundamental e médio até alunos de graduação. Este interesse relaciona-se com o fato da disciplina estar frequentemente presente na mídia e por tratarem de assuntos relativamente interessantes para os alunos, tais como organismos transgênicos, fecundação in vitro, clonagem de organismos, desenvolvimento de célula tronco e outros (VESTENA, SEPEL, LORETO, 2015). É preciso um bom conhecimento em genética para que os alunos sejam capazes de se posicionar criticamente (BONZANINI, 2011).

Apesar de todo este interesse e importância a genética é considerada uma disciplina complexa (BRÃO, PEREIRA, 2015), esta complexidade pode estar relacionada com o fato desta exigir conhecimentos prévios dos alunos (MOREIRA, SILVA, 2001; CANAL, BASTOS, 2001) e por muitas vezes apresentar ligações com outras disciplinas que também são consideradas complexas, tais como bioquímica e biologia molecular.

O conhecimento de genética da população em geral é um problema atual, pesquisa realizada com alunos do ensino médio demonstrou que estes conhecem pouco sobre genética (SCHEID e FERRARI, 2012; FERREIRA et al., 2015a; FERREIRA et al., 2015b) e também no ensino superior os alunos não conhecem tão bem este conteúdo como deveriam (JUSTINA, FERLA, 2006). De uma maneira geral existe uma grande dificuldade em assimilar o conteúdo de genética (BONZANINI, 2011). É preciso que as aulas no Ensino Básico ou Superior possibilitem a compreensão das leis de Mendel e os mecanismos da transmissão dos caracteres hereditários, permitindo ao aluno, inseri-lo em outras disciplinas e relacioná-lo a outros conteúdos (FABRICIO et al; 2006) e ainda serem capazes de opinar em assuntos que são frequentemente abordados pela mídia.

Apesar desta importância e necessidade, verificamos que há um grande problema ao ensinar e aprender genética não só por ser uma disciplina vista como complexa, mas também pelas suas 
peculiaridades. A genética engloba conteúdos que são abordados também por outras disciplinas (BARBOSA, COSTA, 2011) o que pode dificultar a compreensão desta.

Desta forma, acreditamos que seja necessário pensar em metodologias alternativas para que os alunos consigam aprender o conteúdo, para o ensino básico já existem pesquisas relacionadas (BRÃO, PEREIRA, 2015; VESTENA, SEPEL, LORETO, 2015), mas para o ensino superior são poucas. As dificuldades encontradas no ensino básico e superior no ensino de genética são semelhantes (FABRÍCIO et al., 2006). Acreditamos que jogos possam ser boas ferramentas (MACEDO, 1995; BRÃO, PEREIRA, 2015), atividades baseadas na Tecnologia Digital de Informação e Comunicação - TDIC (PEDRO, MIRANDA, COSTA, 2015) e também atividades contextualizadas como a construção de heredogramas (VESTENA, SEPEL, LORETO, 2015).

Assim, uma possibilidade de inserir metodologias alternativas no ensino de genética e favorecer os processos de ensino e aprendizagem é através de oficinas (FERREIRA, et al., 2015a). Denominamos de oficina um conjunto de atividades baseadas em metodologias alternativas cujo objetivo principal é favorecer os processos de ensino e aprendizagem, demonstrando que existem outras possibilidades que não sejam apenas a aula expositiva. Não queremos dizer que esta não é importante, ela é fundamental, porém acreditamos que a aprendizagem acontecesse de forma mais eficaz quando utiliza-se diferentes metodologias.

Considerando especificamente os cursos de licenciatura é ainda mais urgente repensar o ensino de genética, já que os estudantes de hoje em breve serão professores. Assim, é preciso que os cursos de licenciatura em Ciências e Biologia formem professores que realmente conheçam genética, considerando a importância que este tema apresenta para a sociedade e para os alunos. O professor de Biologia enfrenta diversos desafios e deve acompanhar as descobertas científicas e tecnológicas e ainda favorecer a construção coletiva do conhecimento (MOURA, et al., 2103). Assim, acreditamos que seja necessário repensar o ensino de genética nas Universidades.

Considerando a questão da formação docente, os estudantes tendem a copiar seus professores, sendo assim, quando o professor adota metodologias alternativas os estudantes tendem a fazer o mesmo em sua prática docente futura (KENSKI, 2015). É preciso que os formadores integrem em sua prática novas metodologias com o intuito de formar professores que saibam utilizar diferentes metodologias em sua vida profissional. O 
papel dos docentes que atuam em cursos de licenciatura é de extrema importância para a construção do perfil do professor que está sendo formado (VIVEIRO, CAMPOS, 2014).

Desta forma, a presente pesquisa foi realizada em dois momentos distintos. No primeiro foi aplicado um questionário com estudantes de ciências biológicas de uma Universidade Pública de Minas Gerais para verificar o conhecimento que estes apresentam e em seguida os mesmos foram convidados para participar de uma oficina de genética, para aprimorar os conhecimentos obtidos e verificar se esta metodologia é eficiente como uma possibilidade de ensino e aprendizagem em genética e outros conteúdos relacionados.

\section{Métodos}

A presente pesquisa caracteriza-se como qualitativa, na medida em que foi verificado um problema e a partir das dificuldades encontradas, foram pensadas soluções (MINAYO, 2008). A presente pesquisa foi dividida em duas etapas, sendo ambas realizadas em uma Universidade Pública de Minas Gerais, que caracteriza-se pela formação de professores de diferentes áreas.

A primeira etapa foi a aplicação de um questionário com estudantes de Ciências Biológicas da Universidade Pública de Minas
Gerais. O questionário foi baseado em 9 questões abertas: $1-\mathrm{O}$ que é genética; $2-\mathrm{O}$ que a genética estuda; 3 - $\mathrm{O}$ que é gene; 4 Você aprendeu genética no ensino médio; 5 Qual recurso foi utilizado; 6 - Explique a $1^{\mathrm{a}}$ Lei de Mendel; 7 - O que é transcrição de DNA; 8 - Quem foi Mendel; 9 - O que é herança recessiva.

A segunda etapa foi a oficina, que teve como objetivo expor atividades lúdicas no ensino de genética, realizada durante um evento Institucional. Este evento foi aberto para todos os alunos da instituição de todos os cursos (Ciências Biológicas, Educação Física, Letras, Matemática e Pedagogia) fornecidos pela mesma, a fim de mobilizar o meio acadêmico para ampliar e fortalecer sua produção cultural, assim desenvolver nos futuros professores o conhecimentos sobre metodologias alternativas para que facilitem o aprendizado dos alunos e tornem a sala de aula um ambiente mais dinâmico.

A oficina foi apresentada em uma sala de aula com seis jogos didáticos sobre genética. Inicialmente houve uma breve apresentação sobre a oficina, a importância de metodologias diferenciadas em salas de aula e a necessidade de que os alunos aprendam com eficácia. Participaram da oficina 30 estudantes da instituição, alguns destes já exercendo a profissão de professores. Depois desta apresentação dividimos os graduandos em 
grupos de 6 pessoas. Cada grupo ia para um jogo e após (30 minutos) os grupos se deslocavam para novos jogos. A ideia é que cada grupo participasse ativamente de todas as atividades ofertadas.

Apresentamos o jogo dos ácidos nucléicos, que teve como objetivo montar a fita de DNA (ácido desoxirribonucléico) ou de RNA (ácido ribonucléico). O participante pega um cartão aleatório, contendo instruções de como deve ser formada a fita. Neste jogo com peças de madeira, temos um fosfato, uma pentose e uma base nitrogenada, podendo ela ser Adenina, Timina, Citosina, Guanina ou Uracila.

O próximo jogo se chama Jogando com Mendel, que contêm cartas com as quais o objetivo é fazer pares, como um jogo de memória. Porém, depois que encontrar o par de cartas iguais, para ficar com este par e necessário que o aluno acerte a questão proposta na carta. Ganha no final o jogador que estiver com o maior número de pares de cartas respondidas.

O terceiro jogo denominado de show da genética, utiliza-se de tecnologias digitais de informação e comunicação e foi desenvolvido por outros pesquisadores (MARTINES, FUJIHARA, MARTINS, 2008). É semelhante ao show do milhão mas neste jogo se aborda apenas questões de genética.
O quarto jogo foi de tabuleiro com questões de genética. $\mathrm{O}$ participante deveria jogar o dado e, para que pudesse andar o número de casas do dado, era necessário que acertasse a questão de genética. Em determinadas casas, o participante tinha a possibilidade de avançar mais uma casa ou voltar algumas casas e até mesmo ficar uma rodada sem jogar. Ganha o jogador que chegar ao final do trajeto primeiro. Apresentava conteúdos básicos de genética, conforme dificuldade verificada anteriormente.

Elaboramos também o heredograma onde tínhamos recortado círculos (representando as mulheres) e quadrados (representando os homens) entre outros símbolos. O objetivo desta atividade lúdica era que o aluno construísse sua história familiar pelo heredograma. E depois disso havia também questões onde eles desvendavam histórias criando o heredograma. Nesta atividade trabalhamos conceitos básicos da $1^{\text {a }}$ Lei de Mendel, herança autossômica recessiva, dominante e ligada ao sexo.

O ultimo jogo chamado jogo do balão ou balão da genética, se assemelha a um jogo de tiro ao alvo. Balões com questões de genética no seu interior foram fixados na parede. Havia uma distância de três passos com uma linha limite de arremesso. O jogador 
arremessa o dardo e deverá acertar o balão, só marcará o ponto se acertar a pergunta contida no balão. Ganha o jogador que obtiver o maior número de questões acertadas.

No final da oficina, os alunos foram convidados a responder um questionário sobre as atividades desenvolvidas com o objetivo de verificar a eficácia desta metodologia. É importante lembrar que durante a realização da oficina o interesse, participação e envolvimento dos alunos foram observados e anotados para análise futura.

\section{Resultados e Discussão}

Dos estudantes participantes da $1^{\mathrm{a}}$ etapa desta pesquisa $78,9 \%$ afirmaram terem estudado genética no ensino médio. Este é um dado interessante, pois muitas vezes, os alunos não aprendem este conteúdo, como foi verificado no trabalho de Ferreira et al., (2015a). Destes que aprenderam genética no ensino médio, 93,3\% afirmaram que aprenderam apenas com aulas expositivas. É preciso inserir no ensino de ciências outras possibilidades de ensino (VIVEIRO, CAMPOS, 2014).

$\mathrm{O}$ uso de apenas aulas expositivas no ensino de genética vem demonstrando a necessidade de repensar este conteúdo. Para Moura et al (2013) para um bom ensino de genética é preciso que o professor tenha à sua disposição diferentes recursos didáticos, pois a falta destes pode favorecer uma má formação e incompreensão de conteúdos.

Porém quando questionados especificamente sobre o conteúdo de genética verificamos um alto percentual de erros, exceto nas questões sobre o que é genética e o que a genética estuda, nestas encontramos um percentual de acertos de $80,9 \%$.

Verificamos um alto percentual de erros na questão sobre transcrição de DNA (95,3\%), este é um dado negativo, pois este conteúdo é tema de diversas disciplinas do conteúdo de Ciências Biológicas, como Bioquímica, Citologia, Biologia Molecular, Embriologia, entre outras (BARBOSA, COSTA, 2011). Ou seja, o fato destes alunos ainda não terem domínio sobre este aspecto é um grande prejuízo, pois este é um tema fundamental para futuros professores de Biologia.

A dificuldade em compreender sobre ácidos nucléicos foi relatada por Moura et al (2013), demonstrando que este realmente é um tema complexo e de difícil compreensão por parte dos alunos.

A $1^{\text {a }}$ Lei de Mendel é um dos primeiros conteúdos que são apresentados aos alunos em genética, $\mathrm{o}$ alto percentual de erros (81\%) nesta questão é um grande problema, pois este é considerado um pré-requisito para outros conteúdos de genética. É preciso que os estudantes de uma maneira geral e em 
especial futuros professores dominem a $1^{\mathrm{a}}$ e a $2^{\mathrm{a}}$ Lei de Mendel, de modo que sejam capazes de integrar estes conhecimentos em outras partes do conteúdo de genética e também em outras disciplinas (FABRÍCIO et al., 2006).

Poucos alunos conhecem Mendel (66,7\% não conhecem), verificamos um distanciamento do ensino da história da ciência. Este distanciamento tem dificultado os processos de ensino e aprendizagem em genética, seria interessante que o ensino de genética estivesse articulado com a história da ciência (SCHEID e FERRARI, 2012).

Um percentual significativo de alunos também desconhece a herança recessiva $(61,9 \%)$, podemos inferir que desconhecem também aspectos relacionados à diferença entre autossômica e recessiva, os quais são conteúdos fundamentais para o ensino de genética (FABRÍCIO et al., 2006). E 52,4\% dos alunos não sabem o que é um gene.

As dificuldades apresentadas por estes alunos refletem a qualidade do ensino genética. Estes dados sugerem a necessidade de repensar o ensino desta disciplina, concordamos com Ferreira et al (2015b) que é preciso repensar os processos de ensino e aprendizagem de genética e que a inserção de metodologias alternativas é uma possibilidade interessante.

A escolha por mais de uma atividade relacionada com ácidos nucléicos relacionou- se com esta dificuldade que os alunos apresentam neste tópico. Verificamos que os alunos se envolveram efetivamente no jogo dos ácidos nucléicos e no jogo do balão, demonstrando que têm interesse em aprender sobre este tema. Provavelmente reconhecem a importância deste tópico para sua vida profissional.

O jogando com Mendel e o jogo de tabuleiro foram tentativas de favorecer os processos de ensino e aprendizagem de conceitos gerais de genética, não apenas aqueles em que os alunos demonstraram dificuldade, mas outros também que são considerados relevantes dentro do conteúdo de genética. Verificamos que os alunos participaram ativamente, demonstrando interesse em aprender mais. O lúdico favorece a aprendizagem de temas complexos (MACEDO, 1995) e vem se destacando como uma poderosa ferramenta no ensino de genética (BARBOSA, COSTA, 2011). A realização destes jogos foi positiva para os processos de ensino e aprendizagem de genética dos alunos de graduação.

Além disso, destaca-se que estas atividades são desenvolvidas em grupo, no qual um aluno auxilia o outro no processo de ensino e aprendizagem este tipo de atividade vem sendo apontada como significativa para a aprendizagem em ciências, favorecendo uma 
formação mais crítica (VIVEIRO, CAMPOS, 2014).

Sobre o Show da genética, este também destacou-se por ser um jogo e por relacionar as Tecnologias Digitais de Informação e Comunicação, é preciso que os futuros professores aprendam como inserir as tecnologias em suas atividades docentes (KENSKI, 2015). Na sociedade atual os professores não devem se esquecer de integrar em suas práticas docentes atividades relacionadas com as tecnologias.

Trabalhar com o heredograma é importante para que os alunos reconheçam suas relações familiares em diversas gerações (VESTENA, SEPEL, LORETO, 2015). Nesta situação específica, foi muito importante, pois foi o primeiro contato destes alunos com a genética. Além disso, é preciso articular o conhecimento científico com o cotidiano do aluno, esta relação favorece os processos de ensino e aprendizagem (VESTENA, SEPEL, LORETO, 2015).

Através do questionário buscamos compreender qual(is) atividades os alunos consideraram mais interessante. Nesta questão era possível destacar mais de uma. Verificamos que o jogo que mais agradou foi o Jogando com Mendel (57,3\%). É importante lembrar que este foi um jogo construído por este grupo de pesquisa.
Destaca-se também o jogo Show da Genética (42,1\%), vivemos em uma sociedade fortemente marcada pela presença das TDIC, os alunos sentem-se atraídos por esta tecnologia, além disso, cada vez mais os jogos digitais vêm sendo considerados importantes ferramentas para os processos de ensino e aprendizagem (PEDRO, MIRANDA, COSTA, 2015). O jogo do balão foi apontado por $26,3 \%$ e $10,5 \%$ apontaram o heredograma.

Durante a realização da oficina verificamos total participação dos grupos nas atividades propostas. Percebemos uma integração entre os alunos, além de se divertirem eles aprendiam genética. Quando alguém não sabia, um colega se prontificava a responder. Foi um momento de troca de conhecimentos sobre genética.

Dos alunos participantes $5,3 \%$ deram nota 8 para a oficina, $15,8 \%$ nota 9 e $78,9 \%$ deram nota 10. Podemos afirmar que mais de 90\% considerou a atividade como ótima, o que pode ser considerado um resultado positivo, demonstrando que novas práticas devem ser integradas também ao ambiente universitário.

A utilização de práticas inovadoras no ensino de genética tem gerado resultados positivos (BONZANINI, 2011). O grande problema é que as escolas ainda estão utilizando apenas a aula expositiva, dos 
participantes $84,2 \%$ afirmaram que aprenderam genética apenas com esta metodologia.

Acreditamos que apenas aula expositiva não seja suficiente para que os alunos aprendam este conteúdo de forma satisfatória, pois as pesquisas demonstram que alunos terminam o ensino médio sem conhecer aspectos relevantes da genética (SCHEID e FERRARI, 2012; FERREIRA et al., 2015a; FERREIRA et al., 2015b) e ainda os resultados do primeiro momento também demonstram este aspecto. Acreditamos que a Universidade deve favorecer novas práticas com o objetivo de demonstrar para os futuros professores novas possibilidades para o ensino de genética. Como apontado por Kenski (2015) os alunos tendem a imitar as práticas utilizadas pelos seus professores.

Para confirmar este aspecto foi verificado quando questionado se os alunos acreditam que metodologias alternativas favorecem os processos de ensino e aprendizagem de genética, todos concordaram. Desta forma, acreditamos que seja preciso incentivar a utilização de novas metodologias no ensino de genética.

É preciso repensar a formação de professores em especial quando abordamos a questão da genética (MOURA et al., 2013). A utilização de novas metodologias é urgente para favorecer os processos de ensino e aprendizagem, mas também para favorecer a formação de futuros professores que tendem a copiar os formadores (KENSKI, 2015).

\section{Considerações finais}

Os processos de ensino e aprendizagem de genética são considerados difíceis tanto para alunos do ensino médio, quanto para alunos de graduação. É preciso repensar o ensino desta disciplina de modo que os alunos realmente aprendam. Os resultados demonstram que os alunos apresentam dificuldades neste conteúdo, o que relaciona-se muitas vezes com a metodologia. Assim, é preciso repensar o ensino de genética em todos os níveis.

$\mathrm{Na}$ graduação, especificamente na formação de professores de Biologia este é um grave problema na medida em que estes estudantes em breve vão ser professores e, portanto, devem saber ensinar genética para seus alunos. É preciso modificar a formação de professores. Acreditamos que seja preciso inserir novas metodologias no ensino de genética, com o objetivo de favorecer a aprendizagem e futuramente também o ensino desta disciplina É preciso que os formadores utilizem novas metodologias em sua prática docente.

Neste contexto, acreditamos que as oficinas sejam ferramentas poderosas para os processos de ensino e aprendizagem, na 
medida em que em um único momento são apresentadas diferentes formas de se aprender determinado conteúdo, o que favorece os processo de ensino e aprendizagem.

Além disso, através da realização desta atividade foi possível perceber que os

\section{Referências bibliográficas}

BARBOSA, Maralise Dorneles; COSTA, Gustavo Marques. Ácidos Nucléicos: Como entender isso? Genética na Escola. v. 6, n. 1, 2011. Disponível em: <http://media.wix.com/ugd/b703be_6d7a0c4d 6737499b8adc201c525cbb83.pdf>. Acesso em 31 de maio de 2015

BONZANINI, Taitiâny Kárita. Temas da Genética contemporânea e o Ensino de Ciências: que materiais são produzidos pelas pesquisas e que materiais os professores utilizam? In: VIII ENPEC, 2011. Disponível em: < http://www.nutes.ufrj.br/abrapec/viiienpec/res umos/R0389-2.pdf> Acesso em 14 de fev. 2015

BRÃO A. F. S, PEREIRA A. T. B.

Biotecnétika: Possibilidades do jogo no ensino de genética. Revista Eletrônica de Enseñanza de las Ciencias, v. 14, n. 1, p. 5576. 2015. Disponível em: < http://reec.uvigo.es/volumenes/volumen14/R EEC_14_1_4_ex826.pdf> Acesso em $10 \mathrm{de}$ agost. 2015

CANAL, R. R.; BASTOS, F. A Abordagem de Temas Contemporâneos no Ensino de Biologia: análise de uma experiência. Encontro Regional de Ensino de Biologia (1:2001: Niterói) Niterói 2001. 504p.

FABRÍCIO, Maria de Fátima Lima, et al. A compreensão das leis de Mendel por alunos de biologia na educação básica e na alunos sentem-se motivados para realizar atividades baseadas em metodologias alternativas. É preciso investir nestas possibilidades.

licenciatura. Ensaio Pesquisa em Educação em Ciências. v. 8.n. 1, 2006, p. 1-21.

FERREIRA, Keli Eloide; et al., Conhecimentos de genética adquiridos por alunos do ensino médio: a necessidade de repensar os processos de ensino e aprendizagem desta disciplina. In: Encontro Regional de Ensino de Biologia, Anais do III EREBIO, 2015. Disponível em: < http://www.sbenbio.org.br/blog/anais-doencontro-regional-de-ensino-de-biologiaregional-4/>. Acesso em 18 de jan. 2016

FERREIRA, Keli Eloide, et al., Ensino e aprendizagem de genética: estudo em uma escola da rede pública na região metropolitana de Belo Horizonte - MG. In: Encontro Nacional de Pesquisa em Educação em Ciências, Anais do X Enpec, 2015b

JANN, Priscila Nowaski; LEITE, Maria de Fátima. Jogo do DNA: um instrumento pedagógico para o ensino de ciências e biologia. Ciências \& Cognição, v. 15, n. 1, p. 282-293. 2010. Disponível em: < http://www.cienciasecognicao.org $>$. Acesso em 09 de fev. 2015.

JUSTINA, Lourdes Aparecida Della; FERLA, Márcio Ricardo. A utilização de modelos didáticos no ensino de genética - exemplo de representação de compactação do DNA eucarioto. Arqu, Mundi, v. 10, n. 2, p. 35-40, 2006.

KENSKI, Vani Moreira. A urgência de propostas inovadoras para a formação de 
professores para todos os níveis de ensino.

Rev. Diálogo Educ., Curitiba, v. 15, n. 45, p. 423-441, maio/ago. 2015

MACEDO, L. Os jogos e sua importância na escola. Cadernos de pesquisa, 93, p. 5-10, 1995.

MARTINES, Emanuel Ricardo Monteiro; FUJIHARA, Ricardo Toshio; MARTINS, César. Show da genética: um jogo interativo para o ensino de genética. Genética na

Escola, v. 3, n. 2, 2008

MINAYO, Maria Cecília de Souza. O desafio da pesquisa social. In: MINAYO, Maria Cecília de Souza (Org). Pesquisa Social: Teoria, método e criatividade. 27. Ed. Petropolis, RJ: Vozes, 2008. P. 9-30

MOURA, Joseane. et al., Biologia/Genética: $\mathrm{O}$ ensino de Biologia, com enfoque a genética, das escolas públicas do Brasil breve relato e reflexão. Semina: Ciências

Biológicas e da Saúde, Londrina, v. 34, n. 2, p. 167-174, jul./dez. 2013

MOREIRA, M. C. A.; SILVA, E. P. Concepções Prévias: uma revisão de alguns resultados sobre Genética e Evolução. Encontro Regional de Ensino de Biologia (1:2001: Niterói) Niterói, 2001. 504p.

PEDRO, Júlia Márcia Alves; MIRANDA, Karini Maria de Freitas; COSTA, Fernanda de Jesus. Uso do jogo digital como metodologia alternativa para o ensino de plantas medicinais: um estudo em uma escola estadual de Minas Gerais. Revista

Tecnologias na Educação. v. 7, n.2, 2015.

SCHEID, Neusa Maria John; FERRARI, Nadir. A história da ciência como aliada ao ensino de genética. Genética na Escola, v. 11, n. 7, 2012. Disponível em: <http://geneticanaescola.com.br/wphome/wp-content/uploads/2012/10/Genetica-
na-Escola-11-Artigo-07.pdf >. Acesso em 15 de fev. 2015

VESTENA, Rosemar de Fátima; SEPEL, Lenira Maria Nunes; LORETO, Élgion Lúcio da Silva. Construção do heredograma da própria família: Uma proposta interdisciplinar e contextualizada para o ensino médio.

Revista Electrónica de Enseñanza de las Ciencias, v. 14, n. 1, p. 1-16, 2015.

VIVEIRO, Alessandra Aparecida; CAMPOS, Luciana Maria Lunardi. Formação inicial de professores de ciências: reflexões e abordagens das estratégias de ensino e aprendizagem em um curso de licenciatura. ALEXANDRIA: Revista de Educação em Ciência e Tecnologia, v.7, n.2, p.221-249, 2014 